\title{
ARTEFATO DE AUXÍLIO AO TRANSPORTE DE CRIANÇAS EM DIFERENTES MEIOS
}

\section{DEVICE TO AID THE TRANSPORT OF CHILDREN IN DIFFERENT MODES OF TRANSPORTATION.}

\author{
Eduardo Cardoso ${ }^{1}$, M.Sc. \\ Stefan von der Heyde Fernandes ${ }^{2}$, Designer.
}

(1) Doutorando em Design, Universidade Federal do Rio Grande do Sul - UFRGS e-mail: eduardo.cardoso@ufrgs.br

(2) Mestrando em Design, Universidade Federal do Rio Grande do Sul - UFRGS e-mail: stefanufrgs@gmail.com

Palavras-chave: crianças, transporte, design de produto.

O presente artigo apresenta o embasamento teórico, metodológico e os resultados obtidos no desenvolvimento do projeto de um artefato de auxílio ao transporte de crianças em diferentes meios. A pesquisa envolve a apresentação da metodologia, definição do público alvo, assim como a coleta de dados sobre as necessidades dos usuários e seu desdobramento até os requisitos de projeto. Por fim, é apresentado o desenvolvimento do projeto, os estágios de geração de alternativas, validações volumétricas e descrição das funcionalidades do produto.

Key-words: children, transport, product design.

This article presents the theoretical, methodological and results in the development of a project of a device to aid the transportation of children in different modes of transport. The research involves the presentation of the methodology, defining the target, as well as collect data about users' needs and extended to to the project requirements. Finally, we present the development of the project, the stages of generating alternatives, validations and volumetric description of product features.

\section{Introdução}

Os veículos de transporte de todos os tipos procuram atender a solicitações cada vez mais complexas dos consumidores, integrando estilo, economia, desempenho e praticidade com a necessidade de preservação da natureza (LARICA, 2003). O Design de transporte se propõe a desenvolver produtos e sistemas voltados para a mobilidade, criando produtos não somente para um transporte eficiente, como também para a melhor experiência possível para o usuário (BROWN, 2010). Em muitos casos, porém, os projetos não contemplam as necessidades e desejos de todos os usuários, principalmente quando se trata de crianças.

A mobilidade exige atualmente que se tenham artefatos que auxiliem as pessoas no deslocamento de um lugar para outro, e muitas vezes, alguns usuários acabam sendo desfavorecidos. As crianças fazem parte desse grupo que carece de produtos voltados para o seu deslocamento. Não existe no mercado, por exemplo, um assento destinado às crianças que utilizam o transporte público, muito menos um artefato que possa auxiliar no transporte de crianças em diferentes meios.

Desta forma, tendo em vista as atuais necessidades de transporte e a sua importância para o desenvolvimento dos indivíduos ao considerar os ganhos a serem obtidos pelo convívio das crianças com o contexto social, este artigo apresenta o trabalho de desenvolvimento do projeto de um artefato de auxílio ao transporte de crianças em diferentes meios. Este artefato deve atender às necessidades e desejos de todos os envolvidos, sejam eles pais, filhos, avós, tios ou qualquer pessoa que interaja direta ou indiretamente com o produto, e, simultaneamente, incentive o desenvolvimento motor, social e cognitivo da criança.

\subsection{Contextualização}

Papalia (2000) defende que nós, humanos, nascemos com a capacidade de aprender a partir da experiência, da mesma forma, as crianças aprendem com o que veem, ouvem, cheiram, degustam e tocam. Hoje em dia, temos carros, aviões, barcos, trens e vários outros sistemas para satisfazer nossa necessidade de transporte, porém, isto não ocorre 
com relação ao transporte de crianças. O mercado carece de produtos que não limitem-se às cadeirinhas e bebê conforto exclusivos para automóveis.

No setor aeroviário, por exemplo, não existe uma legislação que determine a obrigatoriedade do uso de dispositivos de retenção para crianças em aeronaves. Pesquisa revela que $70 \%$ dos passageiros gostariam de sentar o mais longe possível de crianças no avião (SKYSCANNER, 2010). No entanto, poucas pessoas procuram saber os motivos que levam a criança a chorar tanto em uma viagem de avião, e um desses motivos pode ser o desconforto.

Com relação ao transporte de crianças em veículos rodoviários, no Brasil, foi verificado que apenas 5\% dos veículos analisados transportavam as crianças em cadeiras específicas, e destas, aproximadamente 90\% apresentavam algum tipo de problema de instalação (ONG CRIANÇA SEGURA, 2000 apud. ROMARO, 2005).

Os produtos pertencentes à denominação dispositivo de retenção só foram exigidos por lei no país em 2010, quando a resolução 277 do conselho Nacional de Trânsito (CONTRAN) entrou em vigor, obrigando os condutores de veículos a transportarem crianças menores de sete anos e meio no banco de trás com esse tipo de produto. Uma das principais discussões referentes à resolução 277 está no parágrafo terceiro do art. 1 o qual ressalta que as exigências quanto ao uso do sistema de retenção não se aplicam aos veículos de transporte coletivo, aos de aluguel, aos de transporte autônomo de passageiros (taxi), aos veículos escolares e aos demais veículos com peso bruto total superior a 3,5t.

Neste sentido, o presente trabalho visa desenvolver o projeto de um artefato de auxílio ao transporte de crianças para atender esta notória carência e, principalmente, potencializar o desenvolvimento infantil com segurança.

\section{Fundamentação Teórica}

Para o embasamento teórico da pesquisa buscou-se aprofundar o conhecimento quanto ao desenvolvimento humano nos primeiro anos de vida, bem como o seu crescimento físico e aptidões cognitivas.

\subsection{Desenvolvimento humano}

O campo de estudo do desenvolvimento humano inclui a descrição, explicação, previsão e modificação do comportamento dos indivíduos. Segundo Papalia (2000) não existe uma divisão fixa para o ciclo de vida humano, sendo essas divisões aproximadas e um tanto arbitrárias. Porém, a autora divide o desenvolvimento humano nos primeiros anos de vida em pré-natal, primeira infância, segunda infância e terceira infância. Este trabalho abrange o período da primeira infância, de zero a três anos, e segunda infância, de três a seis anos.

Para a perspectiva contextual, o desenvolvimento humano pode ser compreendido em seu contexto social, ou seja, o indivíduo não é uma entidade isolada que interage com o ambiente e sim uma parte inseparável do mesmo. A teoria de Vygotskky sugere que o desenvolvimento da criança de uma cultura ou de um grupo dentro de uma cultura, como brasileiros de classe média, por exemplo, pode não ser uma norma apropriada para crianças de outras sociedades ou grupos culturais (PAPALIA, 2000).

\subsection{Desenvolvimento físico}

Como visto anteriormente, o desenvolvimento de uma criança pode ser muito variado dependendo de inúmeros aspectos, porém, podemos agrupar as características por idade a fim de facilitar a interpretação do processo de desenvolvimento.

A partir do terceiro mês, o desenvolvimento social da criança evolui. Ela sorri, arrulha e ri, demonstra antecipação e desapontamento através da raiva ou irritação (TILLEY, 2005). No final do quarto mês já é possível sentar sem apoio e ficar em pé com o uso de um apoio e ao final do quinto mês, expressões como vergonha, timidez e autoconsciência começam a surgir (TILLEY, 2005). O peso médio de uma criança de três a cinco meses é de 6,7 quilos e altura de 63,3 centímetros (TILLEY, 2005).

Aos sete meses a criança já tem a capacidade de interagir mais com outras pessoas, demonstrando alegria, medo, raiva e surpresa, ao mesmo tempo sua capacidade motora evolui e é possível segurar com os dedos polegar e indicador (TILLEY, 2005). Em algum momento entre os sete e 11 meses as crianças adquirem a coordenação suficiente para pegar um objeto diminuto como uma ervilha com movimentos semelhantes aos de uma pinça (PAPALIA, 2000). Entre os onze e doze meses a criança consegue ficar de pé sozinha e até caminha com dificuldade, 
começa a imitar sons e a entender algumas palavras além de se mostrar mais curiosa, ficando menos dependente do responsável e explorando o meio ambiente. Aos treze meses já possui a capacidade de subir escadas e buscar resolver problemas por tentativa e erro (TILLEY, 2005). O ambiente pode acelerar ou retardar o desenvolvimento, o uso de andadores, por exemplo, pode desestimular o engatinhar e retardar o caminhar, especialistas em segurança também não recomendam seu uso (COLLINS. 1994 apud PAPALIA 2000). Aos 15 meses, o bebê mediano sabe construir uma torre utilizando dois cubos (PAPALIA 2000). Nesta idade a criança pesa em média 10 quilos e tem o tamanho de 73,7 centímetros (TILLEY, 2005).

Dos dois aos três anos a criança ainda não consegue parar ou se virar de repente ou rapidamente, porém já tem a habilidade de pular uma distância de cinquenta centímetros e pode subir escadas alternando os pés. Começa também a conseguir conversar e se comunicar, palavras novas são aprendidas quase todos os dias e a compreensão é excelente, embora a criança ainda cometa muitos erros de gramática. A criança nesta idade pesa 14 quilos em média e tem altura de 88,3 centímetros (TILLEY, 2005). Por fim, aos quatro anos, a criança começa a ter mais controle para parar, começar a pular e se virar, sobe e desce escadas alternando os pés se tiver apoio. Peso médio de 16 quilos e altura de 95,8 centímetros (TILLEY, 2005).

\subsection{Desenvolvimento cognitivo}

A perspectiva cognitiva aborda as mudanças qualitativas nos processos de pensamento e no comportamento que reflete tais mudanças (PAPALIA, 2000). Piaget (1980 apud PAPALIA, 2000) acreditava que a inteligência da criança é uma capacidade inata de adaptar-se ao ambiente, usando a capacidade sensorial, motora e reflexiva. O Autor também descreveu o desenvolvimento cognitivo em uma série de estágios. Aqui, vamos nos deter ao estágio sensório-motor de Piaget, o qual os bebês aprendem sobre si mesmos e seu mundo por meio do desenvolvimento de suas próprias atividades sensórias e motoras.

No primeiro subestágio (do nascimento até um mês), ao exercitarem seus reflexos inatos, os recémnascidos adquirem certo controle sobre si mesmo, porém, ainda não são capazes de coordenar informações dos sentidos nem pegar objetos que estão olhando. No segundo subestágio (um a quatro meses) os bebês repetem comportamentos agradáveis que primeiramente ocorrem por acaso (como sugar). $\mathrm{O}$ terceiro subestágio (quatro a oito meses) coincide com um novo interesse em manipular objetos, onde os bebês passam a interessar-se mais pelo ambiente e repetem ações que trazem resultados instigantes e prolongam experiências estimulantes. $\mathrm{Na}$ época em que atingem o quarto subestágio (oito a 12 meses) os bebês já coordenam suas ações visando uma meta, como olhar e pegar um chocalho, ou engatinhar até a sala para obter um brinquedo desejado. No quinto suestágio (12 a 18 meses) mostram curiosidade à medida que variam propositadamente suas ações para obter resultados. Eles usam método de tentativa e erro para a resolução de problemas. As crianças no sexto subestágio (18 a 24 meses) são capazes de representar os acontecimentos mentalmente, assim, não se restringem mais à tentativa e erro, $o$ pensamento simbólico permite que comecem a pensar sobre os acontecimentos e antecipem suas consequências sem recorrer à ação.

Este levantamento sobre o desenvolvimento das crianças foi importante para compreender as suas necessidades e delimitar corretamente o público alvo.

\section{Público Alvo}

Para o produto a ser desenvolvido, devemos considerar dois tipos de usuários, o principal, as crianças, e o usuário secundário, os adultos.

\subsection{Usuários Principais}

A resolução 277 do CONTRAN (DENATRAN, 2008) que regulamenta o uso de dispositivos de retenção para crianças em automóveis define cada grupo de criança apenas por idade, de zero a um ano, de um a quatro anos e de quatro a sete anos e meio. Esta classificação se mostra insuficiente, pois não condiz com a realidade. Por isso, foram analisados, também, aspectos antropométricos como peso e tamanho para delimitar o grupo a ser considerado.

Para determinar a abrangência do público alvo, utilizou-se uma relação entre peso, idade e altura. Estes dados foram utilizados segundo a Organização Mundial da Saúde (2006), dados do Ministério da Saúde - MS (2007), dados da Norma ABNT NBR 14400:2009 e dados ergonômicos do livro Medidas do Homem e da Mulher (TILLEY, 2005). Estes dados demonstraram que crianças com diferentes idades podem ter o mesmo tamanho ou o mesmo 
peso, assim como crianças com a mesma idade podem ter tamanho e pesos muito diferentes. Em muitos casos, crianças com menos de um ano não cabem mais no bebê conforto devido à estatura e ao peso, assim como crianças de três anos já tem estatura e peso suficientes para utilizar o assento de elevação, destino às crianças a partir de quatro anos.

A diferença entre a cadeirinha e o bebê conforto está na capacidade de acomodar a criança. Quando recém nascido, o bebê ainda não possui estrutura óssea suficiente para se sustentar, por isso necessita de um dispositivo de retenção que o proteja e o mantenha em uma posição mais inclinada. $\mathrm{O}$ assento de elevação se diferencia por ser destinado a crianças com estatura e peso suficientes para utilizar o cinto de segurança convencional do veículo.

Desta forma, o artefato a ser desenvolvido abrange crianças de seis meses, com peso superior ou igual a 9 quilos e com estatura superior ou igual a 70 centímetros até crianças de quatro anos, com peso inferior a 18 quilos e tamanho inferior a 102 centímetros.

\subsection{Usuários Secundários}

Vale ressaltar que, além das crianças, outros usuários também são importantes para este projeto, como os pais, tios, avós e todas as pessoas que tenham a necessidade de transportar alguma criança. Este projeto visa desenvolver um artefato versátil que proporciona boa interação e usabilidade para todos os usuários. Assim, esses usuários podem ser definidos como adolescentes até idosos, desde que tenham condições de zelar pela segurança da criança.

\section{Metodologia}

Para embasar metodologicamente o presente trabalho, buscou-se referências nas metodologias de desenvolvimento integrado de produto, de Back et al. (2008), assim como em metodologias auxiliares de Baxter (2000), Brown (2010) e Platcheck (2005).

Para Back et al. (2008), o desenvolvimento de produto compreende aspectos de planejamento e projeto, ao longo das fases pelas quais passa $o$ produto, desde planejamento, pesquisa de mercado, projeto do produto, projeto do processo de fabricação, uso, descarte etc. Este processo visa transformar, sistemática e progressivamente, as necessidades dos consumidores em requisitos dos usuários e estes em requisitos e especificações de projeto do produto.

\section{Coleta e Análise de Dados}

Considerando o processo de desenvolvimento de produto, é fundamental a coleta e análise de dados para aprofundar os conhecimentos a respeito das necessidades e requisitos do projeto. Portanto, foram utilizados métodos de coleta de informações de consultores e especialistas por meio de entrevistas e a análise dos produtos similares existentes.

\subsection{Elicitação das Necessidades}

Back et al (2008) argumenta que a voz do usuário se constitui no principal e mais crítico passo para alcançar a qualidade ou a competitividade de produtos. A elicitação de suas necessidades é a frase que expressa o que o usuário precisa, sua vontade, $\mathrm{e}$ sua expectativa (BACK, et al.,2008).

\subsubsection{Observação assistemática}

Para Moraes e Mont'alvão (2009) a observação é um dos meios mais utilizados para se compreender as pessoas, objetos, acontecimentos e situações. As autoras apresentam o método de observação assistemática, que é realizado sem planejamento e controle aprioristicamente definidos. Este método foi utilizado em dois momentos. Primeiramente na Holanda (Europa), a fim de se observar o fenômeno em outra cultura, e posteriormente no Brasil, para observar o contexto local. A diferença na estrutura, tanto do transporte quanto em qualquer setor da economia, reflete as diferentes necessidades de cada público. Na pesquisa realizada no Brasil, por exemplo, foi possível identificar a dificuldade de acesso para as pessoas que conduziam os carrinhos de criança. Isto mostrou a necessidade de desenvolver produtos leves e de fácil manipulação. Com relação ao comportamento das crianças, nas duas pesquisas foi constatado que elas raramente ficam sentadas o tempo todo nos carrinhos, e ao mesmo tempo, que não são capazes de acompanhar o ritmo de um adulto caminhando.

\subsubsection{Análise da tarefa}

Segundo Baxter (2000), o projetista deve examinar detalhadamente a interface homem-máquina, pois através desta análise é possível descobrir problemas complexos e pouco compreendidos. A análise da tarefa explora as interações entre o produto e seu usuário, e seu resultado influencia na criação de novas soluções. A tarefa efetiva refere-se ao 
comportamento do usuário, a maneira como ele procede para alcançar os objetivos sem, necessariamente, seguir o planejamento da tarefa prescrita (IIDA, 2005). Moraes e Mont alvão (2009) explicam que a análise da tarefa tem início com a caracterização da tarefa, que envolve a definição do objetivo, requisitos para sua realização e a presença humana na tarefa. Após é feita a discriminação da tarefa, que consiste em descrever as atividades envolvidas e os meios utilizados para sua realização.

Neste trabalho foram feitas duas análises com artefatos distintos através de registros fotográficos contínuos a fim de observar diferentes posturas e comportamentos dos usuários. Ao término criou-se um diagnóstico da tarefa para que os constrangimentos observados pudessem ser corrigidos no desenvolvimento do projeto. A primeira análise da tarefa foi realizada com dispositivo de retenção denominado cadeirinha, para os grupos de crianças de 9 a 25 quilos de um fabricante nacional. A tarefa prescrita deve seguir diversos passos, porém ao analisar o usuário na sua atividade foi possível perceber que nem todos os processos são realizados. Primeiramente, constatouse que o tamanho da cadeirinha, além de seu peso, dificulta o manuseio do artefato e a sua colocação correta no veículo. Em segundo lugar, observou-se a dificuldade que o usuário apresenta em fixar todos os dispositivos de retenção da cadeirinha junto ao cinto de segurança do veículo. Para a ativação dos componentes de segurança, o usuário se deparou em várias posturas que ocasionam constrangimento gerando fadiga e, consequentemente, dificultam a instalação. Por fim, durante a atividade, a criança sentou por cima do cinto de segurança de cinco pontos da cadeirinha, o que ocasionou maior dificuldade na conclusão da tarefa.

A segunda análise foi realizada com um carrinho de criança de um fabricante multinacional, modelo até 15 quilos (para criança com idade superior a seis meses), em um ambiente residencial. Quanto aos usuários, o objetivo da tarefa do adulto é conduzir o carrinho com segurança, posicionar a criança no carrinho, e colocar o cinto de segurança do carrinho na criança sentada. Com relação ao carrinho, sua capacidade para o armazenamento em volume reduzido exige a presença de alguns sistemas mecânicos e de abertura e travamento. É possível observar que seu volume quando fechado é reduzido, e sua montagem é simples. Ao mesmo tempo, durante a análise, a criança passou o tempo todo observando, também, os movimentos do pai, e muitas vezes tentou imitá-lo, esse comportamento ressalta a necessidade de segurança tanto para o adulto quanto para a criança. Outro aspecto interessante é o uso dos pés para fixar o carrinho aberto, sem ter a necessidade de se abaixar ou levantar o produto para fixa-lo. No entanto, a fixação não é intuitiva. Quando a mãe posiciona a criança no carrinho, sua postura fica em posição prejudicial à coluna. Da mesma forma que ocorreu na análise da tarefa da cadeirinha, novamente o cinto de segurança ficou atrás da criança, fazendo com que os pais fossem obrigados a deslocar a criança para poder posicionar o cinto corretamente. Neste caso, foram necessárias duas pessoas para puxar o cinto de cinco pontos.

\subsubsection{Empatia}

Por ser um projeto que possui o público-alvo principal formado por crianças, entrevistas com estes usuários não seriam muito eficientes. Por isso, buscaram-se outros métodos que fossem eficazes em identificá-las.

Para Brown (2010), devemos "entrar na pele" dos usuários, realizar as mesmas atividades, agir da mesma forma e sentir as mesmas emoções para, assim, poder pensar como o usuário e entender melhor suas necessidades. Brown (2010) denomina esta técnica de tentar ver o mundo através dos olhos dos outros de empatia, um hábito mental que nos leva a pensar como os verdadeiros usuários.

Neste trabalho, o método da empatia foi utilizado em três momentos. Primeiramente, buscou-se realizar um passeio de carro do ponto de vista de uma criança de um ano e oito meses. Em um segundo momento, acompanhou-se a experiência de fazer compras com uma criança de dois anos e cinco meses em um shopping center, e por ultimo, foi feita uma viagem de uma hora e meia em um veículo com a mesma criança de dois anos e cinco meses afim de entender as dificuldades de uma viagem longa.

No contexto desta pesquisa vale salientar que nós, adultos, mesmo sem perceber, temos um campo de visão diferente do das crianças. Desse modo, para poder observar o que a criança enxerga do mundo a sua volta foram feitas gravações de vídeo exatamente no nível dos olhos de uma criança. Como resultado, percebeu-se que os produtos não incentivam a criança a observar e interagir com o ambiente. $\mathrm{O}$ carrinho muito baixo, não permite que a criança observe por cima de um sofá, por exemplo, ou que enxergue algo que está sendo feito encima de 
uma mesa. No passeio dentro de um automóvel a situação é ainda mais limitada, pois a criança não é capaz nem de visualizar a rua e a calçada. Carros são projetados para adultos, por isso, as janelas dos automóveis não são compatíveis ao tamanho das crianças limitando-as apenas a enxergar o céu, os prédios altos, o banco da frente e a porta do veículo. Não é surpresa, portanto, que crianças se sintam entediadas em percursos mais longos.

\section{Desenvolvimento}

Neste capitulo é apresentado o processo de desenvolvimento do projeto do produto, embasado nas metodologias anteriormente apresentadas, de forma a evidenciar os passos até a solução desenvolvida e suas validações.

\subsection{Requisitos de Projeto}

Em tese, todos os usuários expressarão seus interesses como sendo os mais importantes, porém, essa importância poderá ter seu valor alterado se forem considerados outros parâmetros de avaliação (BACK et al., 2008). Através do diagrama de Mudge, foi realizada uma avaliação do grau de importância dos atributos que traduzem os requisitos dos usuários previamente determinados. Por meio desta técnica realizou-se uma avaliação numérica de relações utilizada para definir um grau de prioridade entre as funções, por meio de comparação das possíveis combinações de pares de funções, determinando-se a mais importante dentre as duas. Para a avaliação, as necessidades dos usuários foram agrupadas em palavras-chave, tais como, robustez, segurança e transportabilidade, e cada uma foi confrontada entre as demais no diagrama de Mudge. As qualificações tiveram, então, pesos atribuídos de acordo com a seguinte convenção:

a) grau 1: $O$ atributo $X$ é ligeiramente mais importante que o atributo $\mathrm{Y}$.

b) grau 3: o atributo $X$ é considerado mais importante que o atributo $\mathrm{Y}$

c) grau 5: o atributo $X$ é muito mais importante que $\mathrm{o}$ atributo $\mathrm{Y}$.

Diante dos resultados obtidos no Diagrama de Mudge, foi possível ordenar os atributos avaliados. Aqueles que obtiveram as maiores pontuações foram priorizados para o desenvolvimento do projeto. A ordem de importância e seu peso relativo em percentual:

- Segurança - 27,97\%

- Funcionalidade - 23,78\%

- Ergonomicidade - 20,28\%
- Geometria - 7,69\%

- Transportabilidade - 4,89\%

- Robustez - 4,89\%

- Montabilidade - 2,80\%

- Usabilidade - $2,80 \%$

- Confiabilidade $-2,10 \%$

- Materiais - 2,10\%

- Mantenabilidade - 0,70\%

Após a valoração de importância dos requisitos dos usuários, é realizada a conversão dos requisitos dos usuários em requisitos do projeto, ou seja, inicia-se a tarefa que trata do estabelecimento das características de engenharia do produto, expressas como a "voz da engenharia" (REICH, 1996, apud BACK et al., 2008).

Após da definição dos requisitos de projeto, é definida a prioridade de cada um dos requisitos apresentados. Porém, é importante considerar, também, a importância dos requisitos dos usuários. Isso é relevante já que muitas ações podem atender a um requisito e prejudicar um segundo, ou dois requisitos podem ser inevitavelmente contraditórios (BACK et al, 2008). Para fazer essa priorização, realizou-se a parte central da casa da qualidade (ou matriz de relacionamentos, conforme Hauser e Clausing, 1988, apud Back et al, 2008) do QFD, em que o cruzamento de linhas e colunas é observado como um relacionamento entre requisitos de projeto e usuário. De acordo com Hauser e Clausing (1988, apud Back et al, 2008), o resultado pode indicar que, caso um requisito de projeto não afete nenhum requisito de usuário, este é um parâmetro desnecessário, e também indica a prioridade de cada requisito de projeto relacionado com os requisitos dos usuários.

\subsection{Análise de Similares}

Para a avaliação comparativa dos produtos existentes no mercado foi aplicada a metodologia para o desenvolvimento de produtos sustentáveis de Elizabeth Platcheck (2005) que aborda na fase analítica a atual situação dos produtos no mercado. O objetivo desta fase é preparar o campo de trabalho para a fase posterior, fase de projetação e detalhamento de alternativas. Segundo a autora, a análise serve para esclarecer a problemática projetual, colecionando e interpretando informações que serão relevantes ao projeto. Na fase analítica, é realizada a análise histórica e o levantamento de similares. A análise histórica de similares tem o objetivo de avaliar o desenvolvimento técnico do produto, assim como o meio onde este tem ocorrido. 
Esta etapa é, portanto, uma análise diacrônica do desenvolvimento histórico. Posteriormente é feito o levantamento de similares, que é uma análise sincrônica onde poderá se reconhecer o universo do produto e para evitar reinvenções (PLATCHECK, 2005). Nesta etapa são realizados seis tipos de análise e cada uma é feita segundo critérios traçados pela autora: Análise Estrutural; Análise Funcional; Análise Ergonômica; Análise Morfológica; Análise de Mercado; e Análise Técnica.

Neste trabalho foram feitas duas análises distintas para dois tipos de produtos, carrinho de criança e dispositivo de retenção. A avaliação dos produtos pesquisados foi feita in loco em três lojas de varejo na cidade de Porto Alegre e foram estudados ao todo seis produtos de marcas e modelos variados, realizando para cada um análises diacrônicas e sincrônicas distintas.

\subsection{Conceito, Geração e Seleção de Alternativa}

Após a identificação dos requisitos de projeto, partiu-se para a criação do conceito do produto, ou seja, a ideia que o produto deve transmitir e que represente os seus valores. Baxter (2000) afirma que se deve pensar no estilo do produto, pois este será o seu diferencial perante a concorrência. Para a criação do estilo do produto foram utilizados vários métodos, como painéis visuais, mapas mentais, personas, storyboards e referências visuais. Ao final desse processo já foi possível identificar as características tanto formais quanto simbólicas do produto, dando o suporte necessário para a etapa seguinte de geração de alternativas. $O$ processo de geração de alternativas foi dividido em duas fases: geração através do método de analogias e geração livre, focado em cada componente do produto (FIGURA 1).

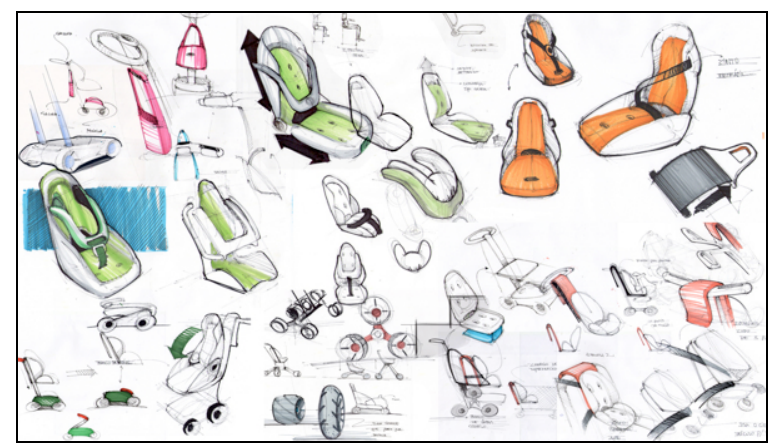

Figura 1: sketches de alternativas.

$\mathrm{Na}$ segunda fase, foram agrupadas as alternativas da etapa anterior para a criação de novas alternativas mais amplas e considerando o produto como um todo. A alternativa selecionada buscou o foco na praticidade. O carrinho colapsa para que possa ser posto diretamente no banco do veículo. As estruturas do carrinho e da cadeirinha estariam unidas e não haveria a necessidade de remoção da cadeirinha para a sua colocação no veículo. Ao chegar com o carrinho perto do veículo, o usuário deve abaixar a cadeirinha até o nível da base do carrinho para que o produto possa ser posto no assento do veículo. Quando o veículo possui cinto de segurança, este deve ser fixado junto à estrutura do carrinho, e a cadeirinha que já está fixa a estrutura do carrinho possui cinto de segurança específico para a criança. Para o uso do produto em um transporte público que não utilize cinto de segurança, como um ônibus público, o próprio carrinho possui um cinto que envolve o banco do veículo. Esta alternativa se destacou pela praticidade, pois não requer muitos mecanismos de fixação ou montagem e desmontagem, já que o carrinho e a cadeirinha são partes inseparáveis do produto. A Figura 2 apresenta as duas configurações possíveis para o uso do produto, como carrinho (à direita) e como cadeirinha (à esquerda).

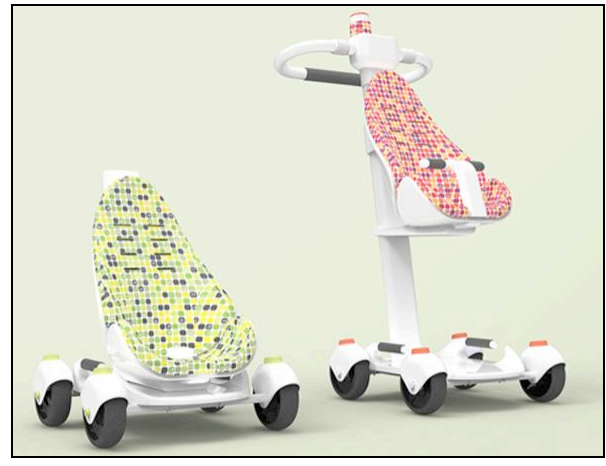

Figura 2: Apresentação do produto

\subsection{Testes volumétricos}

Após a definição da alternativa, desenvolveu-se o modelo virtual para maior detalhamento dos componentes do produto e suas funcionalidades. Este processo foi acompanhado de geração de protótipos em tamanho real para validação da volumetria do produto. Após a modelagem inicial do carrinho criou-se um modelo volumétrico físico para validação do tamanho do produto, bem como de sua usabilidade. A Figura 3 apresenta o teste de validação realizado em um veículo Volkswagen modelo Fox. 


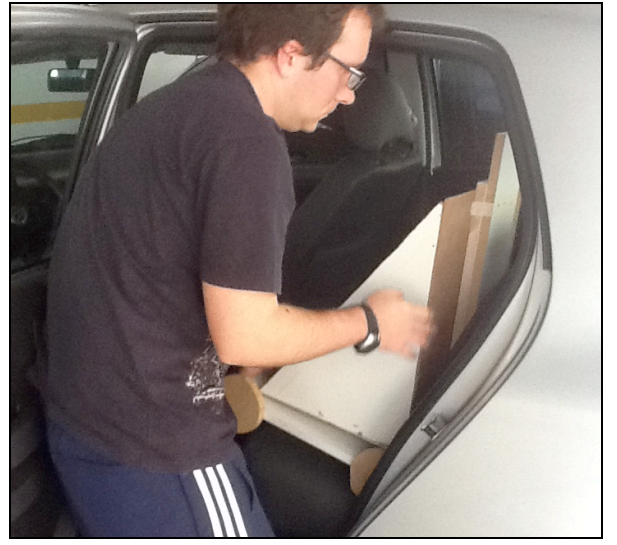

Figura 3: Teste volumétrico.

Observou-se que o produto estava com o dimensionamento correto com relação à altura, porém seu comprimento de 55 centímetros excedia o comprimento do assento do veículo analisado, o que tornava o produto de difícil apoio no assento. Após o teste foi necessário remodelar o produto para que seu comprimento fosse reduzido. Por fim, chegou-se a um comprimento de 46 centímetros, tamanho adequado aos veículos e estável para o transporte como carrinho nas ruas. Este valor foi assumido levando em consideração o comprimento do assento dos veículos que geralmente têm de 45 a 50 centímetros (largura poplítea de um homem do percentil 50 é de 50 centímetros) e o tamanho da base quando o produto fosse utilizado como carrinho. Caso a base do carrinho fosse muito pequena, acarretaria num possível tombamento. Após a execução do segundo modelo virtual foi realizado novo protótipo físico para validação nos veículos e acerca das questões ergonômicas (FIGURA 4).

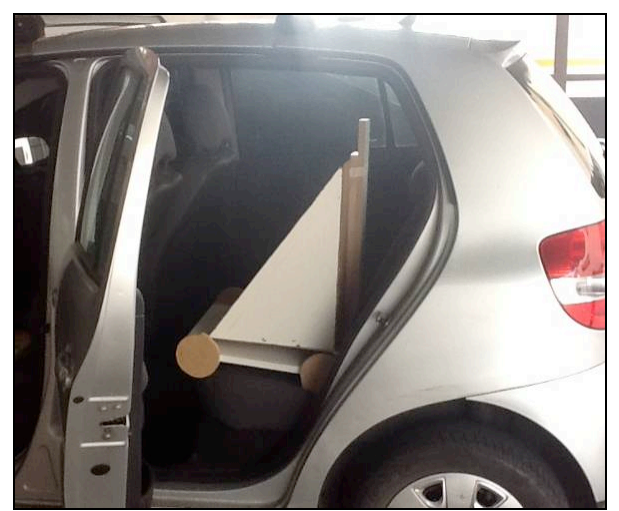

Figura 4: Segundo teste volumétrico.

Para testar as diferentes alturas do produto foram feitos alguns registros fotográficos do produto sendo utilizado por usuários, dois do sexo masculino com estatura de $1,80 \mathrm{~m}$ e $1,68 \mathrm{~m}$, e um do sexo feminino com estatura de $1,54 \mathrm{~m}$. A regulagem de altura do carrinho possibilita ajustes de acordo com a estatura do usuário. A Figura 5 mostra que mesmo em usuários extremos o carrinho satisfaz plenamente as suas necessidades ergonômicas.

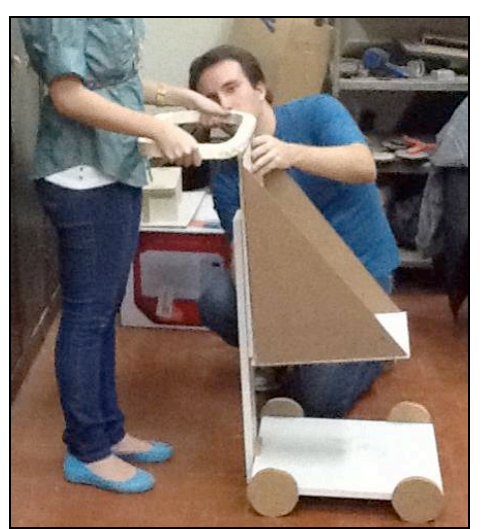

Figura 5: Teste com usuários de diferentes alturas.

Após as validações volumétricas, foi possível refinar a modelagem virtual do produto e ao fim do processo de detalhamento de cada componente, foi realizado um estudo de estabilidade do produto.

\subsection{Especificações de Funcionalidade}

Aqui serão apresentadas as funcionalidades do produto, suas aplicações como cadeirinha e como carrinho, seus diferentes usos, e informações específicas dos componentes.

Com relação à altura do carrinho, o extensor possui 14 níveis de altura sendo possível ajustá-la para diferentes estaturas. Além disso, a cadeirinha é fixa ao extensor, por isso, independentemente do tamanho do usuário, a cadeirinha sempre estará a uma altura confortável para remoção e colocação da criança, bem como para interação (FIGURA 6).

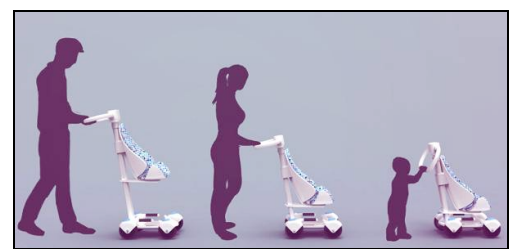

Figura 6: Diferentes possibilidades de altura.

O ajuste de altura possibilita também que o produto seja utilizado como cadeirinha para refeições. Para isso, sua altura deve ser ajustada e em seguida as rodas traseiras devem ser travadas para que não haja deslocamento.

O guidão é semelhante aos de bicicletas de cicloturismo, chamados de multigrip, que proporcionam múltiplos pontos de pega, podendo o usuário utilizá-lo da maneira mais conveniente - 
ideal para longos trechos. O carrinho possui, também, três níveis de inclinação, primeiramente o nível ativo, que condiciona a criança em uma posição com o encosto mais vertical proporcionando mais interatividade entre $o$ ambiente e a criança, $o$ segundo é o nível de descanso, proporcionando uma inclinação para deixar a criança em uma posição mais relaxada, e por fim o nível de soneca, em que a criança fica mais horizontalmente posicionada.

Com relação a fixação da cadeirinha, para veículos que possuem assentos com cinto de segurança devese passar o cinto abdominal entre as pegas na base da cadeirinha, e a parte transversal acima da cadeirinha, entre o guidão e a cadeira. Desta forma, a estrutura do produto simula um corpo humano tornando o cinto de segurança do veículo uma proteção para a criança. A maioria dos veículos de transporte público não possui cinto de segurança, por isso, o produto dispõe de um cinto de fixação que envolve o encosto do assento. Dessa forma a criança pode estar segura mesmo em transportes em que não é oferecido ou mesmo exigido nenhum tipo de dispositivo de segurança.

\section{Considerações Finais}

Em todo o desenvolvimento do trabalho pode ser visto a carência existente no ato de transportar crianças, e, ao mesmo tempo, é possível perceber o quão importante é o convívio e foco no usuário para o desenvolvimento de projetos, me especial para o público infantil. Crianças que crescem interagindo com o ambiente têm ganhos no desenvolvimento de habilidades cognitivas e sociais, e se capacitam de forma mais plena para a vida adulta. O projeto teve como objetivo, além de projetar de forma concreta um dispositivo de auxílio ao transporte de crianças em diferentes meios, apresentar a problemática, e alertar sobre os riscos que a falta de produtos destinados a este publico pode ocasionar.

Buscou-se também discutir sobre o tema de um público que não expressa de forma verbal suas necessidades. Durante a análise de similares pode-se observar que os produtos existentes no mercado são de fato destinados aos adultos, com menor preocupação com o conforto e o bem-estar da criança. O desenvolvimento de um produto especificamente projetado para satisfazer os desejos e necessidades dos usuários principais torna-o de grande importância para futuros projetos, a fim de que estes mudem a filosofia de projetar para o comprador para projetar para os usuários.
É espantoso verificar que após um ano de intensa pesquisa não foi possível encontrar nenhum projeto semelhante, da mesma forma em que é absurdo saber que muitas crianças morrem diariamente por falta de dispositivos corretos que atendam às suas necessidades. Atualmente vemos uma crescente movimentação em prol da defesa da segurança das crianças. Como apresentado na no capitulo de contextualização, desde 2010 é obrigatório o uso de dispositivo de retenção em veículos de passeio. Porém, sabe-se que isto é ainda muito pouco perto da grande complexidade de produtos que existem para o transporte público que ainda não são contemplados. Assim, ainda não existe no mercado nenhum produto destinado ao transporte em ônibus, trem e taxi, tornando o transporte de crianças nesses veículos algo extremamente perigoso. $\mathrm{O}$ produto apresentado é, mais que um projeto, um alerta aos demais projetistas e usuários sobre a importância da existência de produtos que visem a segurança e o conforto das crianças.

\section{Referências Bibliográficas}

ABNT NBR 14400, Segunda edição: 15.04.2009, Valida a partir: 15.05.2009. Disponível em: $<$ http://www.abntcatalogo. com.br/norma.aspx? $\mathrm{ID}=40023>$ Acesso em: 8 out. 2011.

BACK, N.; OGLIARI, A.; DIAS, A.; SILVA, J. C. Projeto integrado de produtos: planejamento, concepção e modelagem. Barueri, SP: Manole, 2008.

BAXTER, Mike. Projeto de produto: guia prático para o design de novos produtos. 2 ed. São Paulo: Edgard Blücher, 2000.

BROWN. Tim. Design thinking: uma metodologia poderosa para decretar o fim das velhas ideias. Rio de Janeiro: Elsevier, 2010.

DENATRAN. Resolução CONTRAN 277, 28 maio 2008. Disponível

em:<http://www.denatran.gov.br/download/Resoluc oes/RESOLUCAO_CONTRAN_277.pdf $>$ Acesso em: 2 set. 2011.

IIDA, I. Ergonomia - projeto e produção. $2^{\mathrm{a}}$ edição. São Paulo Ed. Edgar Blücher Ltda, 2005.

LARICA, Neville Jordan. Design de automóveis: Arte em função da mobilidade. Rio de Janeiro: 2AB, 2003.

MINISTÉRIO DA SAÚDE. Caderneta de Saúde da Criança. 2007. Disponível em: 
$<$ http://portal.saude.gov.br/portal/saude/visualizar_t exto.cfm?idtxt $=29889 \&$ janela $=1>$ Acesso em: 4 out. 2011.

MORAES, Anamaria de. MONT`ALVÃO, Claudia R. Ergonomia: conceitos e aplicações. Rio de Janeiro: 2AB, 2009.

PLATCHECK, Elizabeth Regina. Metodologia de ecodesign para o desenvolvimento de produtos sustentáveis. Porto Alegre, RS, 2005.

ROMARO, Marcus. Comportamento dos Cintos de Segurança Infantis em Impactos Veiculares (confrontação com os requisitos de segurança veicular da Norma NBR 14400 da ABNT). Universidade Estadual de Campinas, 2005.
SKYSCANNER, THE SYDNEY MORNING

HERALD. Screaming child lands Qantas in court JUL/2010. Disponível em

$<$ http://www.smh.com.au/travel/travelnews/screamingchild-lands-qantas-in court20100720-10iu6.html? comments $=193>$. Acesso em: 21 set. 2011.

TILLEY, Alvin R. As medidas do homem e da mulher: fatores humanos em design. Porto Alegre: Bookman, 2005.

WORLD HEALTH ORGANIZATION. The WHO Child Growth Standards. Disponível em: $<$ http://www.who.int/childgrowth/en/>. Acesso em: 13 nov. 2011. 